\title{
Tuning Sample Length Effect on Mass Transport in Current Carrying Cu-Si \\ Thin Film Systems via Interfacial Engineering
}

\author{
Nalla Somaiah and Praveen Kumar ${ }^{1}$
}

Department of Materials Engineering, Indian Institute of Science, Bangalore 560012

\section{Supplemental Material}

(a)

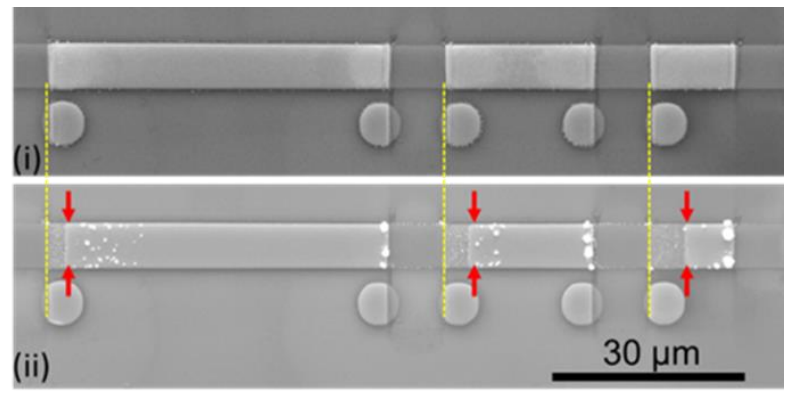

(b)

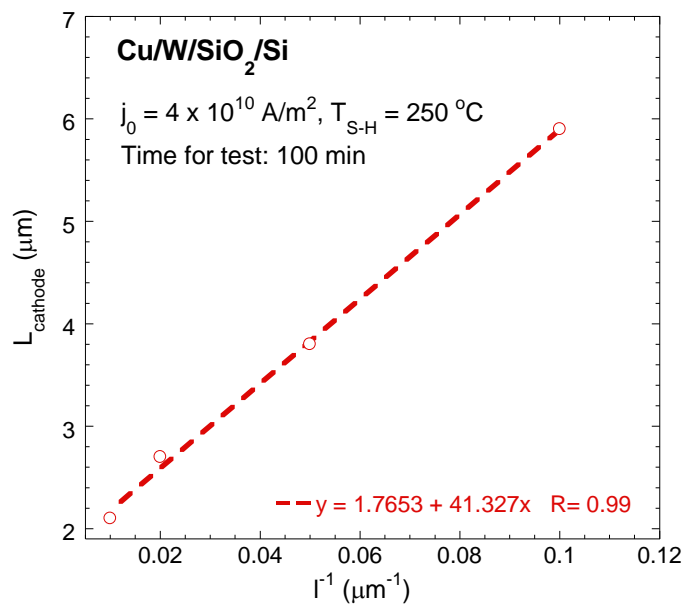

Fig. S1: (a) SEM micrograph of a Cu-W sample comprising 3 stripes and (b) variation of extent of the depletion zone at the cathode, $L_{\text {cathode, }}$ as function of the inverse of the sample length, $l^{-1}$. Both of these figures confirm existence of inverse Blech length phenomenon in $\mathrm{Cu}-\mathrm{W}$ system. Electromigration test was performed for 100 min by passing an electric current of density of $4 \times 10^{10} \mathrm{~A} / \mathrm{m}^{2}$ while maintaining a substrate temperature of $250{ }^{\circ} \mathrm{C}$. (Figure is adopted from the ref 6. Permission will be taken from APS once ref. 6 is published)

\footnotetext{
${ }^{1}$ Corresponding author (P. Kumar): E-mail - praveenk@iisc.ac.in, Tel: +91-80-22933369
} 


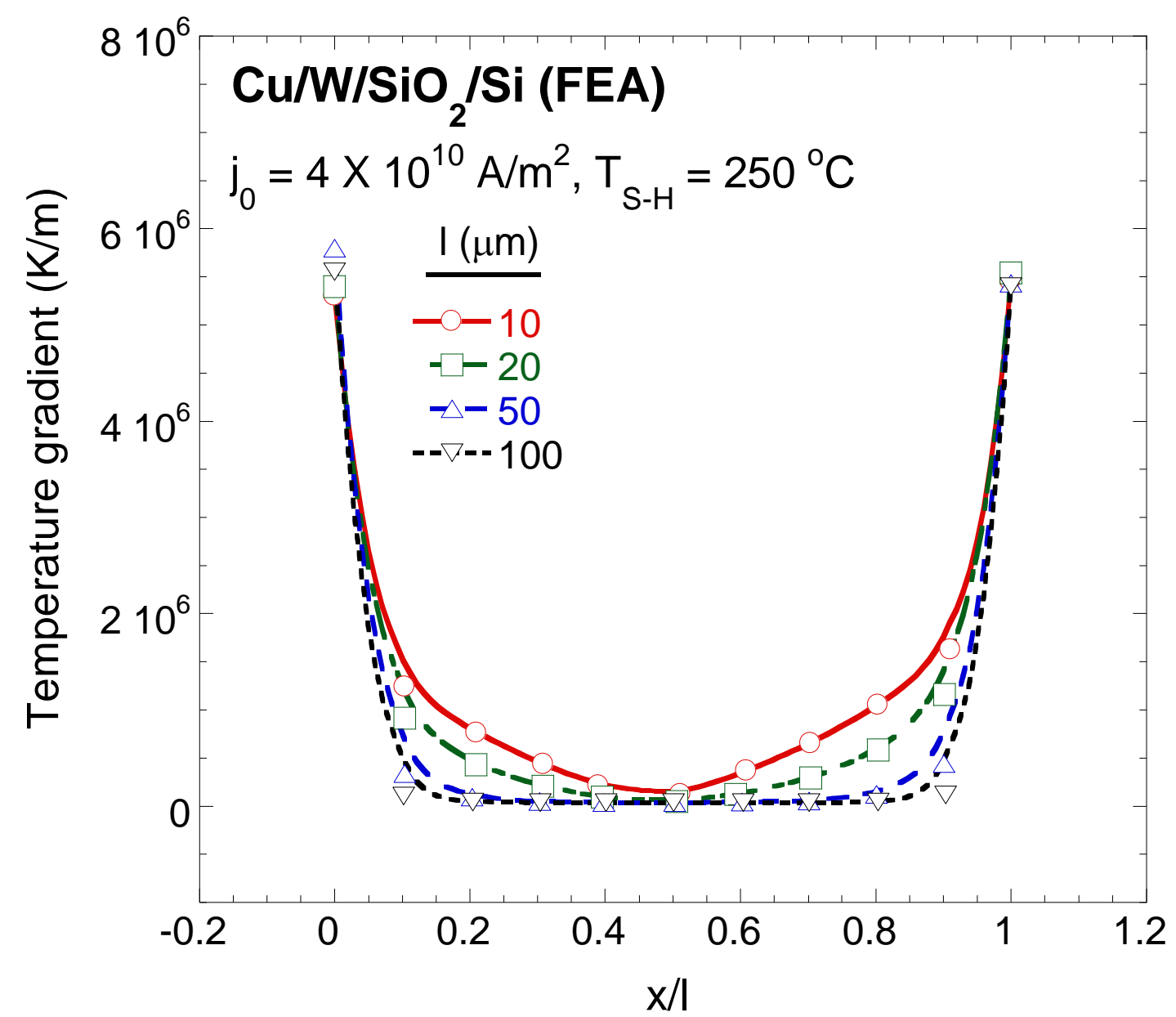

Fig. S2: Variation of the temperature gradient in $\mathrm{Cu}$ films segments in $\mathrm{Cu}-\mathrm{W}$ sample as function of the normalized distance. The $\mathrm{x}$-axis is normalized by dividing a distance by the total length of the sample. (Figure is adopted from the ref 6. Permission will be taken from APS once ref. 6 is published) 